\title{
Estimating Consumers' Knowledge and Attitudes Towards Over-The-Counter Analgesic Medication in Greece in the Years of Financial Crisis: The Case of Paracetamol
}

\author{
Christos Kontogiorgis - Evangelia Nena - Eleftherios Berberoglou • \\ Kyriaki Moschoni $\cdot$ Spyros Polyzois $\cdot$ Athanasios Tselemponis $\cdot$ Theodoros C. Constantinidis
}

To view enhanced content go to www.paintherapy-open.com

Received: November 3, 2015 / Published online: December 22, 2015

(C) The Author(s) 2015. This article is published with open access at Springerlink.com

\section{ABSTRACT}

Introduction: Non-prescription

over-the-counter (OTC) drugs are widely used by patients to control aches, pain, and fever. One of the most frequently used OTC medications worldwide is paracetamol (acetaminophen). The aim of the present study was to fill the current knowledge gap regarding the beliefs and attitudes of people in Greece associated with the use of paracetamol during the years of financial crisis.

Methods: The present study employed a sample of individuals visiting community pharmacies in the second largest city of Greece, Thessaloniki. All participants anonymously answered a questionnaire regarding their beliefs and characteristics of paracetamol

Electronic supplementary material The online version of this article (doi:10.1007/s40122-015-0042-x) contains supplementary material, which is available to authorized users.

C. Kontogiorgis $(\bowtie) \cdot$ E. Nena · E. Berberoglou .

K. Moschoni · S. Polyzois · A. Tselemponis .

T. C. Constantinidis

Laboratory of Hygiene and Environmental

Protection, Medical School, Democritus University

of Thrace, Alexandroupolis, Greece

e-mail: ckontogi@med.duth.gr consumption. Their answers were then statistically analyzed.

Results: The generic paracetamol compound was shown to be more well known than the original. A significant percentage of participants, ranging between $9.9 \%$ and $33.7 \%$, falsely believed that certain medications [mainly non-steroidal anti-inflammatory drugs (NSAIDs)] contained paracetamol. Participants' age, level of education, and gender were shown to be predictive of this false belief. Additionally, $11.1 \%$ of participants believed that the maximum allowed daily dose of paracetamol was higher than the correct one. Better educated individuals were less likely to consume alcohol in parallel with paracetamol (odd ratio 0.230, 95\% confidence interval 0.058-0.916, $P=0.037)$.

Conclusion: Paracetamol is commonly used, both in its original and generic forms. However, a significant number of individuals confuse it with NSAIDs. Age, level of education, and gender are important determinants of the characteristics of paracetamol consumption. It seems that patients prefer to take paracetamol on their own decision during the financial crisis. 
Keywords: Age; $\quad$ Education; $\quad$ Gender; Over-the-counter medication; Pain medicine; Paracetamol; Pharmacoepidemiological study

\section{INTRODUCTION}

Non-prescription over-the-counter (OTC) drugs are widely used by patients to control aches, pain, and fever $[1,2]$. Worldwide, paracetamol (acetaminophen) is one of the most frequently used OTC medications [3, 4]. Likewise, consumption of paracetamol is widely spread in Greece [5]. It is generally accepted that paracetamol use is safe. Numerous benefits of the use of OTC medications have been recognized, such as the increase in patients' autonomy, the decreased frequency of physician visits, and the subsequent reduction of costs for the National Health System [6, 7]. Nevertheless, no such treatment can be without the risk of adverse events and interactions with prescribed medications or other substances, mainly due to limited knowledge of the constitution of other drugs $[8,9]$, overdosing, or side effects [10, 11].

Previous studies have indicated that self-medication should be done under special caution. Even for OTC medications like paracetamol, most people are not familiar with the possible risks and should be advised by health professionals before side effects occur [3]. However, little is known about what people believe about mild analgesics, especially paracetamol, and whether these beliefs are associated with the way they use them. Available data suggest that paracetamol is in general considered as 'weak' and hence less risky than other medications [12]. Furthermore, Hawton et al. [8] have shown that paracetamol availability significantly influenced self-poisoning behavior. Only 35\% of British and American adolescents, who participated in the research, have admitted that they would have taken an overdose, even though they were aware of the acute side effects [13]. Additionally, it has been reported that $39 \%$ of the adult population in the USA continues taking OTC paracetamol over a 1-month period [14].

Between 2000 and 2009, Greece had the highest growth in the European Union in real per capita pharmaceutical expenditure; therefore, it is of high priority to evaluate the knowledge of consumers [15]. During the years of financial crisis in Greece, there was a decrease in pharmaceutical expenditure $(-33.8 \%)$ due to the decrease in the price of medications, although there was an increase of up to $7 \%$ in OTC market consumption [16, 17]. As mentioned previously, paracetamol is one of the most widely spread and used OTC medications. Thus, the aim of the present study was to fill the current knowledge gap regarding the beliefs and attitudes of people in Greece associated with the use and probably over-use of paracetamol, especially in the context of the ongoing financial crisis.

\section{METHODS}

\section{Study Population}

For 40 days, members of the research group approached consecutive adult individuals, who were intending to purchase analgesic medication in 10 pharmacies in the commercial center of Thessaloniki, a city in Northern Greece with a metropolitan area of approximately 690,000 inhabitants. Participants were invited to answer the questionnaire, after the scope of the study was explained to them. Inability to communicate in 
Greek language, mental handicap, age $<18$ years and unwillingness to participate were the exclusion criteria.

\section{Questionnaire}

Individuals who consented to participate anonymously answered a questionnaire comprising 14 questions. The questionnaire, translated to English, is available in the online supplementary material. Prior ethics committee review was not undertaken, since questionnaires were answered anonymously and no physical intervention was performed to the participants. The questionnaire was developed by the study investigators and piloted on paracetamol consumption. The questionnaire took approximately $20 \mathrm{~min}$ to complete. Specifically, participants were asked to select those medications containing paracetamol from among a range of commonly used analgesics available in the Greek market. Additionally, common reasons for paracetamol use were explored, as well as participants' knowledge on the side effects of paracetamol, the maximum daily dose, parallel use with alcohol, and characteristics of consumption by patients with chronic disorders.

\section{Statistical Analysis}

Descriptive statistics were calculated and Chi-square analysis was used to identify proportional differences between subgroups. Additionally, binary logistic regression analysis was used to assess the determining factors for correct knowledge and attitude towards paracetamol use. All data analysis and statistics were performed using SPSS statistical software version 17.0 (SPSS Inc., Chicago, IL, USA).

\section{RESULTS}

\section{General Characteristics of Participants}

Out of 317 individuals approached in the 40 day study period, 252 met the inclusion criteria and consented to participate by answering the questionnaire (a response rate of 79.5\%). Participants had a mean age of 45.3 years (standard deviation \pm 17.9 years), 123 were male, and 129 were female. Regarding participants' level of educational, the majority were high school graduates (40.5\%). Additionally, $10.3 \%$ were healthcare professionals. Participants' characteristics are displayed in Table 1.

\section{Answers to the Questionnaire}

\section{Does this Medication Contain Paracetamol?}

This question focused on participants' knowledge of paracetamol and of commonly used medications containing paracetamol. The possible answers included a series of well-known analgesics among which, only four contained solely paracetamol as the active compound; the rest were medications categorized as non-steroidal anti-inflammatory drugs (NSAIDs) and antispasmodics (Table 2).

Logistic regression analysis revealed that neither the gender [odds ratio (OR) 0.996, 95\% confidence interval (CI) 0.106-1.105] nor the age (OR 0.897, 95\% CI -0.003-0.003) of participants were factors that could predict the correct answers for all questions about medications containing paracetamol. However, a lower level of education was associated with a higher probability for incorrectly answering all questions regarding paracetamol-containing drugs (OR 0.019, 95\% CI 0.017-0.183).

Analysis was also performed on the answers regarding each one of the medications 
Table 1 General characteristics of the participants

\begin{tabular}{ll}
\hline Characteristics & Value \\
\hline Total number of participants $(N)$ & 252 \\
Gender (\%) & 48.8 \\
Male & 51.2 \\
Female & \\
Age, years (mean \pm standard deviation) & $45.3 \pm 17.9$ \\
All participants & $47.4 \pm 18.1$ \\
Males & $43.3 \pm 17.6$ \\
Females & \\
Educational background (\%) & \\
Middle school graduate $(9$ years) & 14.3 \\
High school graduate (12 years) & 40.5 \\
University graduate (16-17 years) & 30.6 \\
Postgraduate or PhD & 4.4 \\
Healthcare professional (physician, dentist, pharmacist, or nurse) & 10.3 \\
\hline
\end{tabular}

Table 2 Active compounds and trade names of the medications mentioned in the questionnaire

\begin{tabular}{ll}
\hline Active compounds & $\begin{array}{l}\text { Participants reporting that the active } \\
\text { compound is paracetamol (\%) }\end{array}$ \\
\hline Paracetamol & \\
Original & 62.7 \\
Generic 1 & 75.8 \\
Generic 2 & 21.4 \\
Paracetamol + codeine & 29.4 \\
NSAIDs & \\
Mefenamic acid (original) & 33.7 \\
Acetyl-salicylic acid & 20.2 \\
$\quad$ (original) & \\
Nimesulid (original) & 16.7 \\
Diclofenac (original) & 9.9 \\
Antispasmodics & \\
Hyoscine-N-butylbromide & 13.5 \\
(original) & \\
\hline NSAID non-steroidal anti-inflammatory drugs
\end{tabular}

separately. The medications included in the questionnaire were among the most popular OTC drugs in Greece. The original paracetamol medication was quite well recognized by participants with a university diploma, postgraduate studies, and the healthcare scientists when compared to individuals with lower levels of educational (Table 3).

The same result was observed with one of the generic paracetamol medications, which was again better recognized by participants with a university diploma, postgraduate studies, and the healthcare scientists when compared to individuals with lower levels of educational (Table 3).

However, only $21.4 \%$ of participants recognized the other generic product as a paracetamol-containing medication. Again, the participants level of education played critical role (OR for less educated versus well educated $\quad 0.442, \quad 95 \% \quad$ CI $\quad 0.228-0.854$, $P=0.015)$, as well as age, where increased age is related to better knowledge of the generic paracetamol medication (Table 3). 


\section{Paracetamol + Codeine}

The combination of paracetamol + codeine is a popular analgesic medication in the Greek market. In line with previous analyses, a higher level of education was associated with participants' knowledge of the medication's substance, and the better educated participants presented more critical use of this medication. Relatively, gender seemed to play an important role, with female participants more frequently using this medication as a regular paracetamol-containing analgesic medication than males (Table 3).

\section{Mefenamic Acid}

Mefenamic acid-containing drugs are also widely used as anti-inflammatory and analgesic medications; they were falsely considered to be a paracetamol-containing medication by $33.7 \%$ of participants. This knowledge seemed to be influenced by the participants' level of education, with better educated participants presenting better knowledge. This was also influenced by age, with younger individuals having better knowledge.

\section{Acetyl-Salicylic Acid}

Almost one of five (20.6\%) participants believed that acetyl-salicylic acid contained paracetamol. Gender was a major determinant for this false belief, with males having a higher probability of giving the incorrect answer than females.

\section{Diclofenac Sodium}

Similar results were also observed with diclofenac sodium, where gender seemed to influence participants' knowledge on whether diclofenac contains paracetamol. Male gender was also associated with this false belief [OR $=3.162$ (1.105-9.047), $P=0.032]$.
Table 3 Logistic regression analysis of the factors predicting the correct answer to each question with a statistical significance

\begin{tabular}{llll}
\hline Medications/factors & OR & $95 \%$ CI & $P$ value
\end{tabular}

Paracetamol

Original

$\begin{array}{llll}\text { Age }^{\mathrm{a}} & 0.995 & 0.978-1.012 & 0.003 \\ \text { Education }^{\mathrm{b}} & 2.147 & 1.109-4.159 & 0.023\end{array}$

Generic 1

Education

$2.778 \quad 1.433-5.387$

0.002

Generic 2

$\begin{array}{llll}\text { Age }^{\mathrm{a}} & 0.969 & 0.950-0.989 & 0.003 \\ \text { Education }^{\mathrm{b}} & 0.442 & 0.228-0.854 & 0.015\end{array}$

Paracetamol + codeine

$\begin{array}{lllr}\text { Gender }^{\mathrm{c}} & 2.340 & 1.277-4.285 & 0.006 \\ \text { Education }^{\mathrm{b}} & 4.186 & 2.244-7.807 & <0.001\end{array}$

Mefenamic acid

$\begin{array}{llll}\text { Age }^{\mathrm{a}} & 0.979 & 0.963-0.995 & 0.009\end{array}$

Acetyl-salicylic acid

$\begin{array}{llll}\text { Age }^{\mathrm{a}} & 0.975 & 0.956-0.996 & 0.017 \\ \text { Education }^{\mathrm{b}} & 0.403 & 0.202-0.804 & 0.010\end{array}$

Diclofenac sodium

$\begin{array}{llll}\text { Gender (male) } & 3.162 & 1.105-9.047 & 0.032 \\ \text { Education }^{\mathrm{b}} & 0.316 & 0.111-0.905 & 0.032\end{array}$

Hyoscine-N-butylbromide

\begin{tabular}{llll} 
Age $^{\mathrm{a}}$ & 0.966 & $0.942-0.990$ & 0.005 \\
Gender $^{\mathrm{c}}$ & 2.351 & $1.056-5.238$ & 0.036 \\
\hline
\end{tabular}

$C I$ confidence interval, $O R$ odds ratio

${ }^{a}$ Older ( $>65$ years) vs. younger ( $<65$ years)

b Better educated (university graduates, postgraduates or $\mathrm{PhD}$, and health scientists) vs. less educated (middle school graduates and high school graduates)

${ }^{c}$ Males vs. females

\section{Hyoscine-N-Butylbromide}

A well-known medication containing hyoscine-N-butylbromide was falsely believed 
to contain paracetamol by $13.5 \%$ of participants. This belief was negatively associated with age, with younger participants demonstrating better knowledge of this medication, and was associated with gender, with female participants demonstrating better knowledge than males.

\section{What is your Main Reason for Using \\ Paracetamol?}

The main reason participants gave for using paracetamol was headache $(46.8 \%)$, while arthralgia, cold and flu, and fever were less common reasons given. Gender was a significant factor for determining the main reason for using paracetamol. For male participants, the second most common reason for paracetamol use was arthralgia, while for females, the second most common reason was for cold and flu (Table 4).

\section{What is the Maximum Daily Dose of Paracetamol?}

The majority of participants $(56.4 \%)$ believed that $0.5-1 \mathrm{~g}$ (1-2 tablets of $0.5 \mathrm{~g}$ ) of paracetamol was the maximum daily dose. A significant proportion (20.2\%) answered that the maximum dose was $3 \mathrm{~g}$ and only $12.3 \%$ of participants correctly answered that the maximum daily dose of paracetamol was $4 \mathrm{~g}$. Interestingly, $11.1 \%$ of participants answered that the maximum daily dosage of paracetamol is $5 \mathrm{~g}$, which is in fact toxic (Fig. 1).

\section{Does Paracetamol Have Any Side Effects?}

More than one-third of participants (36.1\%) believed that paracetamol had no side effects or toxic effects on human health. This approach may lead to the use of paracetamol without certain precautions, for example, people with limited awareness on the side effects of medications can be more easily addicted to such use.

Who has Suggested that you Use Paracetamol? Paracetamol is an OTC medication and hence no prescription is necessary. However, it is important to investigate who advised the participants to use paracetamol. Interestingly, this advice did not come from a healthcare professional for $43.3 \%$ of participants, while $36.9 \%$ of participants used paracetamol after suggestion from their physician and $19.8 \%$ were advised by their pharmacist. Suggestions from relatives and friends seemed to be crucial for paracetamol consumption (26.2\%), followed by the Internet (13.9\%). Only a small proportion (3.2\%) of participants were influenced by advertisements in the media and on social media (Table 5).

Regarding the use of paracetamol without suggestion from a physician or pharmacist, it appeared that this was associated with gender and age. It was much less likely for male participants than females to take paracetamol without suggestion from a physician or pharmacist (OR 0.256, 95\% CI 0.030-0.497, $P=0.025)$. Regarding age, frequent use without prescription was reported by younger participants (average age $40.5 \pm 17.2$ years) versus those reporting an average use of 2-3

Table 4 Most common reasons reported by participants for use of a paracetamol-containing medication

\begin{tabular}{llcc}
\hline Reasons & \multicolumn{3}{l}{ Participants $(\%)$} \\
\cline { 2 - 4 } & Total & Males & Females \\
\hline Headache & 46.8 & 40.3 & 53.7 \\
Arthralgia & 18.7 & 27.1 & 9.8 \\
Cold and flu & 15.5 & 12.4 & 18.7 \\
Fever & 15.5 & 16.3 & 14.6 \\
Dizziness & 3.6 & 3.9 & 3.3 \\
\hline
\end{tabular}




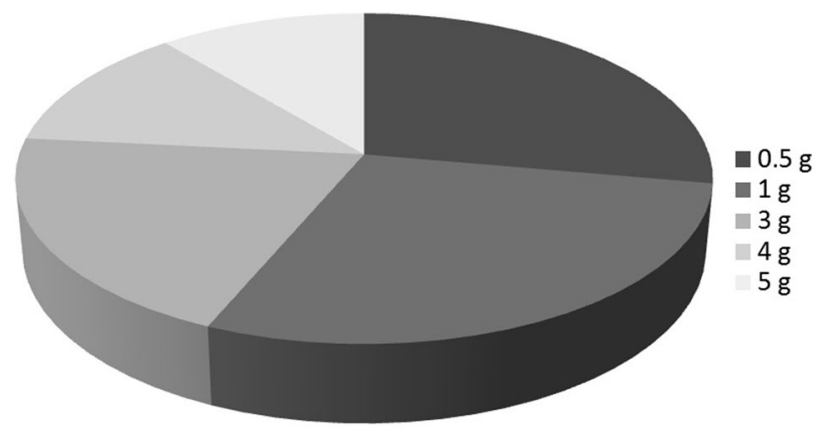

Fig. 1 Participants' belief on the maximum daily dose of paracetamol

Table 5 Participants' answers about who suggests the use of paracetamol

\begin{tabular}{lll}
\hline $\begin{array}{l}\text { Source of } \\
\text { information }\end{array}$ & $\begin{array}{l}\text { Participants } \\
(\%)\end{array}$ & $\begin{array}{l}\text { Age } \\
(\text { mean } \pm \text { SD) }\end{array}$ \\
\hline Physician & 36.9 & $47.3 \pm 15.2$ \\
Pharmacist & 19.8 & $49.5 \pm 18.3$ \\
Relatives and friends & 26.2 & $41.1 \pm 19.5$ \\
Internet & 13.9 & $39.1 \pm 16.7$ \\
Advertisements (TV, & 3.2 & $33.8 \pm 15.8$ \\
$\quad$ radio, internet) & & \\
\hline
\end{tabular}

times a week (average age $60.6 \pm 17.1$ years; $P<0.001)$. Thus, it appeared that younger women were more likely to intake paracetamol without appropriate consultation with a healthcare professional.

\section{Would you Buy Paracetamol from Places Other than a Pharmacy?}

Regarding the setting where someone would buy paracetamol, $54.4 \%$ of those who answered stated that they would not mind buying it from a store, other than a pharmacy. Further analysis on this group of individuals, indicated that females $(54.7 \%)$ and less educated people (60.6\%) were more likely to buy paracetamol elsewhere. There was only a slight difference in the mean age of individuals who would buy paracetamol elsewhere $(44.3 \pm 1.4$ years $)$ compared with those who would only buy paracetamol from pharmacies ( $46.5 \pm 1.7$ years).

If you are Patient with a Chronic Disease, Do you Use Paracetamol Without Informing your Physician?

Participants with a chronic disease (83 of 252 participants) were less likely to communicate with their physician before using paracetamol (OR 0.985, 95\% CI 0.970-1.000, $P=0.046$ ) than those without a chronic disease in their history. Less than the half of participants with a chronic disease asked a healthcare professional before consuming paracetamol (physicians: $45.6 \%$ and pharmacists: $39.5 \%)$.

\section{Do you Consume Alcohol Before or After Paracetamol Intake?}

These questions referred to the combined use of alcohol and paracetamol. Interestingly, 28.5\% of participants reported drinking alcohol immediately or in the first $2-3 \mathrm{~h}$ after paracetamol use. Further analysis revealed that older participants were less likely than younger participants to drink alcohol after paracetamol use (OR 0.982, 95\% CI 0.966-0.998, $P=0.032$ ). On the other hand, regarding paracetamol use following the consumption of alcohol it was revealed that the level of education was a prognostic factor, with better educated 
participants being less likely to use paracetamol after alcohol consumption (OR 0.230, 95\% CI 0.058-0.916, $P=0.037)$.

\section{DISCUSSION}

This was the first study on the knowledge and attitude of the Greek population towards the use of paracetamol, a widely distributed analgesic. The OTC market in Greece has changed over the last few years. The widespread availability of paracetamol in the almost 12,000 pharmacies all over Greece and a poor understanding of the side effects and toxicity of paracetamol significantly influence its use. In addition, the lack of information about the symptoms of paracetamol toxicity seems to play a key role in self-medication with paracetamol by adolescents.

From the current study, it appears that Greek consumers are not sufficiently aware of the potential risks associated with paracetamol use. It is quite interesting that a significant proportion of consumers use medications like NSAIDs, believing that they are similar to paracetamol. Incorrect knowledge was shown to be dependent on consumers gender, level of education, and age. Younger women were shown to be the most likely users of paracetamol without consulting a physician or a pharmacist, with the majority being advised to use paracetamol by a friend or relative. Likewise, participants with a chronic disease were more likely to use paracetamol without prior consultation with a physician or a pharmacist, probably due to the fact that they feel more comfortable in using different treatment modalities due to their medical condition.

It seems that older people are quite closer to the pharmacists that can be explained by the fact that pharmacies in Greece are widely spread and there is a strong connection between pharmacists and the local community. On the other hand, younger people seem to be more likely to be informed and influenced by the Internet, on social media, and through various advertisements.

Additionally, there is lack of knowledge regarding the maximum daily dose of paracetamol, with the majority being sub-treated, raising a question about therapeutic efficacy and consumers' contentment. On the other hand, a non-negligible proportion also indicated that they would consume increased dosages reaching toxic levels.

Strengths of the study are the data from OTC market in Greece that are being presented for the first time. There has been no other analyses on individuals' knowledge and attitudes regarding OTC medications in Greece. It should be also emphasized that this research took place during the ongoing financial crisis in Greece. Due to the financial crisis, there has been a significant increase in unemployment, and a decrease in salaries and pension. It has become quite expensive to visit a private doctor. Furthermore, the number of physicians in public hospitals is reduced and the remaining physicians had less time to spend on each one of their patients. Thus, in many cases people are forced to decide their own treatment. Under these circumstances, and since paracetamol-containing medications are quite cheap, as a consequence their use is expanded, therefore, studying consumers' attitude became necessary. A limitation is that the study was conducted solely in an urban area (city center of Thessaloniki) and therefore lacks data from those living in rural and semi-urban areas.

\section{CONCLUSIONS}

Certain issues need to be addressed regarding the OTC use of paracetamol, namely raising awareness of the potential side effects, reason of intake, and the recommended daily dose. 
Future actions should be heading in the direction of recognizing factors that influence consumers' view of analgesics and OTC drugs in general, given that these beliefs are associated with proper use, as well as with over-use.

\section{ACKNOWLEDGMENTS}

No funding or sponsorship was received for this study or publication of this article. All named authors meet the International Committee of Medical Journal Editors (ICMJE) criteria for authorship for this manuscript, take responsibility for the integrity of the work as a whole, and have given final approval to the version to be published.

Disclosures. All the authors have nothing to disclose.

Compliance with ethics guidelines. Prior ethics committee review was not undertaken per guidance in the National Statements on Ethical Conduct in Human Research [5, 6].

Open Access. This article is distributed under the terms of the Creative Commons Attribution-NonCommercial 4.0 International License (http://creativecommons.org/licenses/ by-nc/4.0/), which permits any noncommercial use, distribution, and reproduction in any medium, provided you give appropriate credit to the original author(s) and the source, provide a link to the Creative Commons license, and indicate if changes were made.

\section{REFERENCES}

1. Blenkinsopp A, Bond C. Over-the-counter medication. London: British Medical Association; 2005.
2. Albert NM, Rathman L, Ross D, et al. Predictors of over-the-counter drug and herbal therapies use in elderly patients with heart failure. J Card Fail. 2009;15:600-6.

3. French DP, Delyth ZH. Reasons for the use of mild analgesics among English students. Pharm World Sci. 2008;30:79-85.

4. Food and Drug Administration. Acetaminophen overdose and liver injury-background and options for reducing injury. 2012. http://www.fda.gov/down loads/AdvisoryCommittees/CommitteesMeeting Materials/Drugs/DrugSafetyandRiskManagement AdvisoryCommittee/UCM164897.pdf. Accessed 28th Oct 2015.

5. Tsiligianni IG, Delgatty C, Alegakis A, Lionis C. A household survey on the extent of home medication storage. A cross-sectional study from rural Crete. Greece. Eur J Gen Pract. 2012;18:3-8.

6. Brass EP. Changing the status of drugs from prescription to over the counter availability. N Engl J Med. 2001;345:810-6.

7. Sinclair HK, Bond CM, Hannaford PC. Long term follow-up studies of users of nonprescription medicines purchased from community pharmacies: some methodological issues. Drug Saf. 2001;24:929-38.

8. Hawton K, Simkin S, Deeks J, et al. UK legislation on analgesic packs: before and after study of long term effects on poisonings. BMJ. 2004;329:1076-80.

9. Morgan O, Griffiths C, Majeed A. Impact of paracetamol pack size restrictions on poisoning from paracetamol in England and Wales: an observational study. J Public Health (Oxf). 2005;27:19-24.

10. Indermitte J, Reber D, Beutler M, Bruppacher R, Hersberger KE. Prevalence and patient awareness of selected potential drug interactions with self-medication. J Clin Pharm Ther. 2007;32:149-59.

11. Davies MJ, Krska J, Mackridge AJ, Khela A, Brown K, Museredza F. The general public's attitudes towards medicinal products. Int $\mathrm{J}$ Pharm Pract. 2009;17:A23-4.

12. Roumie CL, Griffin MR. Over-the-counter analgesics in older adults: a call for improved labelling and consumer education. Drugs Aging. 2004;21:485-98.

13. Gilbertson RJ, Harris E, Pandey SK, Kelly P, Myers W. Paracetamol use, availability, and knowledge of toxicity among British and American adolescents. Arch Dis Child. 1996;75:194-8. 
14. Kaufman DW, Kelly JP, Rohay JM, Malone MK, Weinstein RB, Shiffman S. Prevalence and correlates of exceeding the labeled maximum dose acetaminophen among adults in a US-based internet survey. Pharmacoepidemiol Drug Saf. 2012;21:280-1288.

15. Foundation for economic and industrial Research, Pharmaceutical market in Greece. 2013. http:// www.iobe.gr/docs/research/RES_05_A_21072014_ REP_GR.pdf. Accessed 28th Oct 2015.
16. Organisation for Economic Co-operation and Development, Health at a Glance, 2011. OECD Publishing, 2014. http://dx.doi.org/10.1787/ health_glance_eur-2014-en. Accessed 28th Oct 2015.

17. Organisation for Economic Co-operation and Development. Health at a Glance: Europe 2014. OECD Publishing, 2014. http://dx.doi.org/10.1787/ health_glance_eur-2014-en. Accessed 28th Oct 2015. 